\title{
Variability in the indication of brain CT scan after mild traumatic brain injury. A transnational survey
}

\author{
Alfonso Lagares ${ }^{1,2}$ (]) Ana María Castaño-Leon ${ }^{1} \cdot$ Marion Richard ${ }^{3} \cdot$ Parmenion Philip Tsitsopoulos $^{4} \cdot$ Julian Morales $^{5}$.

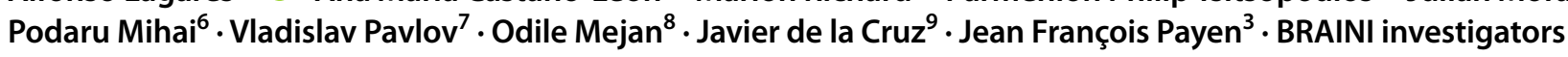

Received: 13 November 2021 / Accepted: 30 January 2022

(c) The Author(s) 2022

\begin{abstract}
Purpose Clinical guidelines have been developed to standardize the management of mild traumatic brain injury (mTBI) in the emergency room, in particular the indication of brain CT scan and the use of blood biomarkers. The objective of this study was to determine the degree of adherence to guidelines in the management of these patients across four countries of Southern Europe.

Methods An electronic survey including structural and general management of mTBI patients and six clinical vignettes was conducted. In-charge physicians from France, Spain, Greece and Portugal were contacted by telephone and email. Differences among countries were searched using an unconditional approach test on contingency tables.

Results One hundred and eighty eight physicians from 131 Hospitals (78 Spain, 36 France, 12 Greece and 5 Portugal) completed the questionnaire. There were differences regarding the in-charge specialist across these countries. There was variability in the use of guidelines and their adherence. Spain was the country with the least guideline adherence. There was a global agreement in ordering a brain CT for patients receiving anticoagulation or platelet inhibitors, and for patients with seizures, altered consciousness, neurological deficit, clinical signs of skull fracture or signs of facial fracture. Aging was not an indication for $\mathrm{CT}$ in French centres. Loss of consciousness and posttraumatic amnesia were considered as indications for CT more frequently in Spain than in France. These findings were in line with the data from the 6 clinical vignettes. The estimated use of CT reached around 50\% of mTBI cases. The use of S100B is restricted to five French centres.

Conclusions There were large variations in the guideline adherence, especially in the situations considered to order brain CT after mTBI.
\end{abstract}

Keywords Mild traumatic brain injury $\cdot$ Adult $\cdot$ Computed tomography $\cdot$ Clinical guidelines $\cdot$ Survey

The members of BRAINI investigators are listed in

acknowledgements.

Alfonso Lagares

alfonlag@ucm.es

1 Department of Neurosurgery, Hospital Universitario 12 de Octubre, Universidad Complutense de Madrid, Instituto de Investigación imas12, Madrid, Spain

2 Department of Surgery, Facultad de Medicina, Universidad Complutense de Madrid, Madrid, Spain

3 Department of Anesthesia and Intensive Care, University Grenoble Alpes, Centre Hospitalier Universitaire Grenoble Alpes, Grenoble Institut Des Neurosicences, INSERM, U1216 Grenoble, France

4 Department of Neurosurgery, Hippokration General Hospital, Aristotle University School of Medicine, Thessaloniki, Greece
5 Servicio de Urgencias, Hospital Universitario Gregorio Marañón, Madrid, Spain

6 Servicio de Urgencias, Hospital Universitario del Tajo, Aranjuez, Spain

7 bioMérieux, Medical Affairs, Chemin de LÓrme, Marcy-L’Étoile, France

8 bioMérieux, Clinical Unit, Chemin de lÓrme, Marcy l’Étoile, France

9 Instituto de Investigación imas12, Hospital Universitario 12 de Octubre, SAMID, Madrid, Spain 


\section{Introduction}

Traumatic brain injury (TBI) is a common cause of admission to emergency departments. Most TBI patients admitted to EDs are classified as mild TBI (mTBI), defined by presenting with a Glasgow Coma Score (GCS) between 13 and 15 [1-3]. The main concern managing these patients is the ability to detect those who could deteriorate and therefore are in need of further assessment with a cranial CT [2, 4-6] and may eventually require an intervention. Several prediction rules and guidelines have been developed to estimate the risk of presenting an intracranial lesion, and thus be in risk of further deterioration. Some of these rules have gained international recognition, such as Canadian CT head rule [7], the New Orleans criteria [8], or the National Institute of Health and Care Excellence (NICE) guidelines [9]. These guidelines and others designed locally [10], use different clinical and examination factors to determine the need of performing cranial $\mathrm{CT}$ based on the risk of presenting intracranial lesions. These guidelines formulated indications for a cranial CT and therefore how management of mTBI should be carried out in a safe and effective manner.

Despite the development of clinical guidelines, different studies have reported wide variability in the management of mild TBI in developed countries and especially among European countries [11]. Though most patients could be managed without the need of a cranial CT, the variability in patient management determine CT overuse in these patients in many occasions.

Blood biomarkers could serve as objective tools to help in the assessment of the need for cranial CT in the management of these patients $[3,12]$. Among a number of candidates S100B is the only biomarker included in a guideline, the Scandinavian guidelines [13, 14], to rule out the need for head CT in mTBI patients. However, the use of this guideline or the biomarker in southern European countries is unknown.

BRAINI is a prospective multicentre observational European Project aiming to determine the diagnostic accuracy of an automated assay for the measurement of serum GFAP and UCH-L1 in a cohort of patients with mTBI who received a CT scan as the standard of care [15]. As the goal of the BRAINI study is to assess the value of two novel biomarkers in the management of mTBI, we searched to assess how mTBI is currently managed in the emergency room in France and Spain, including Hospitals of different sizes, case load and variable resources. A sample of Hospitals from another two European countries (Greece and Portugal) was also obtained for comparison. Besides which situations should be considered for brain $\mathrm{CT}$, we collected information from in-charge physicians regarding their management of mTBI patients in the emergency room.
The goal of this study was to investigate how mTBI is being managed in different Southern European countries with regards to which speciality is responsible for the management of mTBI patients, guideline use and adherence, indications for cranial CT and use of S100B in the management protocols in these countries.

\section{Methods}

\section{Study design}

A survey was designed using as a base the questionnaire developed by Center TBI investigators [11]. Certain modifications were made to include questions regarding structure of care of patients with mild TBI, including medical speciality in charge of care, guidelines used and estimated compliance, use of CT scan and S100B. Six clinical case vignettes were designed to cover different types of clinical situations and check guideline adherence as a separate part embedded in the questionnaire (See supplementary material).

Questionnaires were built into a REDCap database and sent in digital form. For Spain and France the questionnaire was translated into Spanish and French respectively. The English version was used for Portugal and Greece. Centres were contacted by phone personally or email to help get responses from them. National Spanish Society of Neurosurgery (SENEC) and French Society of Emergency Medicine contributed to the dissemination of these questionnaires.

Different members of departments at each hospital answered questionnaires to collect as much information as possible as well as different points of view from the same centre. Data from clinical vignettes were used as single answers from each clinician (one response per each physician filling this part of the questionnaire). For the rest of the questionnaire, answers from more than one physician per centre were averaged.

\section{Statistical analysis}

For statistical analysis descriptive statistics were used. Categorical variables are presented as frequencies and percentages. Contingency tables were built to determine differences among countries regarding the conditions that prompted the ordering of a CT scan and the results from the clinical vignettes. A procedure designed to test significance in contingency tables using an unconditional approach (i.e. without applying first and omnibus test and further analysis of residuals) using a bootstrap correction for multiple testing as suggested by Garcia-Pérez et al. [16], was used for the analysis of differences among countries. All the analysis were performed using the computing environment $\mathrm{R}$ [ $\mathrm{R}$ Core Team (2015), which is a language and environment for statistical 
computing. R Foundation for Statistical Computing, Vienna, Austria; http://www.R-project.org/]. Graphical analysis was performed by means of the Likert package [17] and analysis of contingency tables by means of ACT code for R [16].

\section{Results}

\section{General results}

One hundred and eighty eight (188) physicians from 131 Hospitals completed the questionnaire (Table 1). Spain (78 centres) and France (36 centres) had the highest frequency rates of answers. Physicians from different types of Hospitals were invited to answer the survey in both countries. In most occasions a neurosurgeon was available for consultation 24 h 7 days a week. Most Hospitals were public financed hospitals though in Spain and France also private financed hospitals were reached. In most centres there was a technician available on site to perform a cranial CT. In those not having this resource, a technician was available in less than an hour.

There were differences between countries regarding the specialist in charge of mTBI patients. In some centres, more than one specialist was responsible for the management of mTBI patients in the emergency department setting, a factor that could increase local variability in the management. Emergency medicine is the main responsible speciality for the management of mTBI in the majority of French centres and most Spanish centres. In some Spanish centres Neurosurgeons are still responsible for directly managing mTBI, and there is a mix of several other specialities responsible in other Spanish centres. Portugal has a similar mix, as in the five centres that completed the questionnaire there is a mix of specialities responsible for the management of mTBI patients (general surgeons, neurosurgeons and emergency medicine physicians). In Greece mTBI seems to be managed mainly by neurosurgeons and general surgeons.

Most centres have an area in the ED for temporary observation of these patients. The median time for management of these patients in the ED of the different centres was $8 \mathrm{~h}(\mathrm{IQR}=3)$, without differences among the different countries surveyed.

\section{Adherence to guidelines}

There is a wide variability in the guidelines declared to be used by the different surveyed centres (Fig. 1). In France and Portugal higher homogeneity was seen where consensual local French guidelines and NICE guidelines seem to be more frequently used. In Greece also NICE guidelines are more frequently used. A wide diversity of guidelines are used in Spain. In Spain as many as 30\% of the centres declared that they do not follow any specific guideline. Regarding the estimated guideline compliance, both Portugal and France seem to be the countries that adhere most to guidelines. Greece and Spain did not reach 50\% of estimated good guideline compliance (less than 50\% of centres estimated guidelines are used in most cases or always, more than $50 \%$ adherence to guidelines).

Table 1 Characteristics of 131 centers responding to the survey

\begin{tabular}{|c|c|c|c|c|c|}
\hline & Spain $(n, \%)$ & France $(n, \%)$ & Greece $(n, \%)$ & Portugal & All \\
\hline \multicolumn{6}{|l|}{ Hospital type } \\
\hline Level 1 (few specialities, limited lab) & $3(4)$ & $16(45)$ & 0 & 0 & $19(15)$ \\
\hline Level 2 (5-10 specialities) & $22(28)$ & $17(48)$ & $2(14)$ & $1(20)$ & $42(32)$ \\
\hline Level 3 (all resources) & $53(68)$ & $3(7)$ & $10(86)$ & $4(60)$ & $70(54)$ \\
\hline Public financing & $74(95)$ & $31(86)$ & $12(100)$ & $5(100)$ & $122(93)$ \\
\hline Neurosurgeon available (24/7) & $46(59)$ & $31(86)$ & $5(42)$ & $5(100)$ & $87(66)$ \\
\hline Trauma ICU on site & $36(46)$ & $24(67)$ & $5(42)$ & $5(100)$ & $70(53)$ \\
\hline Technician to perform CT scan $24 / 7$ on site & $74(95)$ & $29(81)$ & $10(83)$ & $5(100)$ & $118(90)$ \\
\hline \multicolumn{6}{|c|}{ Who is responsible for the management of mild TBI } \\
\hline Emergency medicine & $81(66)$ & $38(84)$ & $2(11)$ & $2(20)$ & $125(62)$ \\
\hline Neurologist & $2(2)$ & $0(0)$ & $0(0)$ & 0 & $3(1)$ \\
\hline Neurosurgery & $25(20)$ & $3(6)$ & $11(61)$ & $3(30)$ & $43(21)$ \\
\hline Trauma surgeon & $3(2)$ & $2(4)$ & $0(0)$ & $1(10)$ & $8(4)$ \\
\hline General surgeon & $5(4)$ & $0(0)$ & $5(28)$ & $4(40)$ & $14(7)$ \\
\hline Intensivist & $6(4)$ & $2(4)$ & $0(0)$ & 0 & $8(4)$ \\
\hline Observation area in the ER for mild TBI & $74(95)$ & $34(94)$ & $9(75)$ & $4(80)$ & $121(92)$ \\
\hline
\end{tabular}

More than one answer was allowed regarding especially responsible for mTBI management 

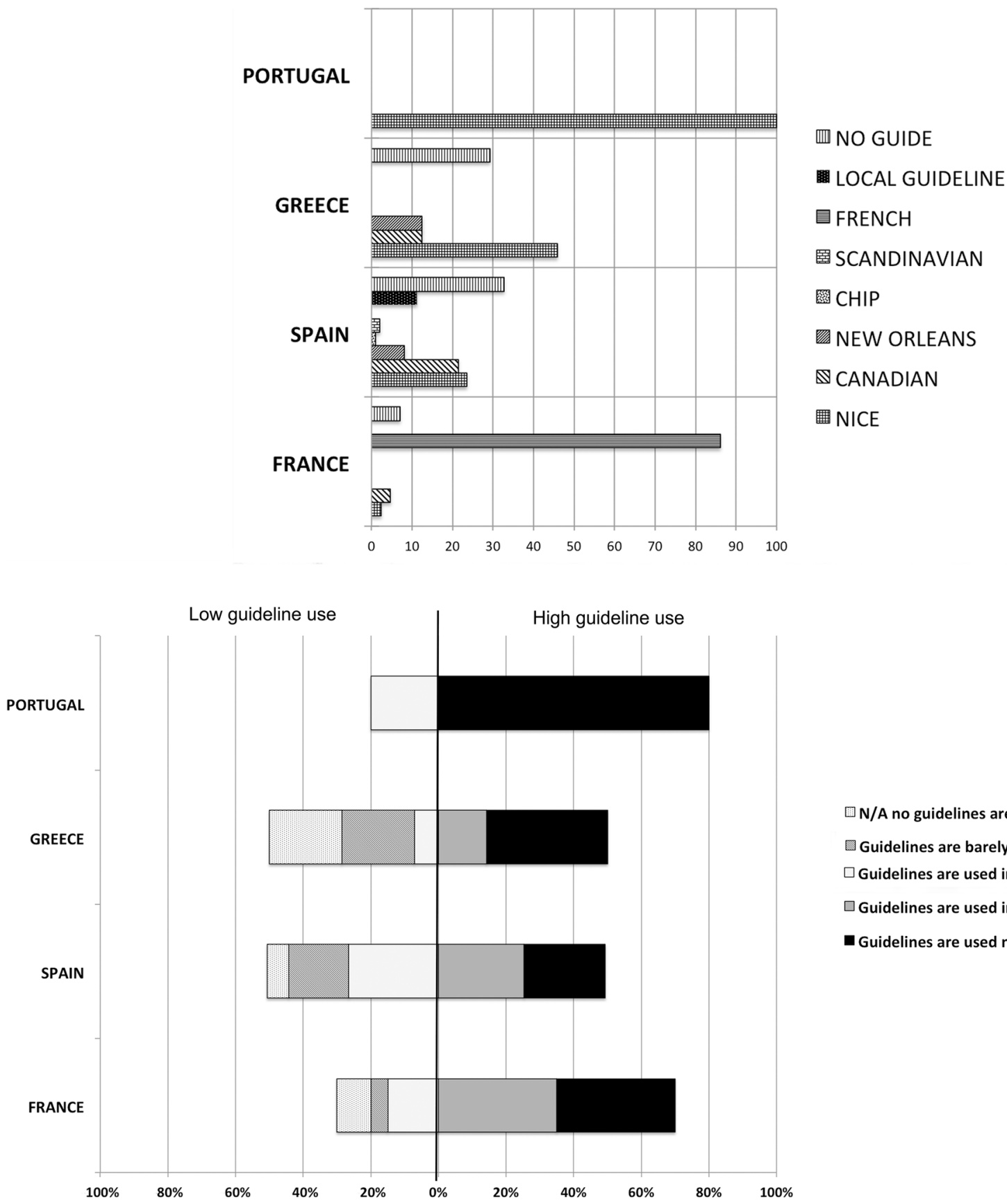

\footnotetext{
$\square$ N/A no guidelines are used

In Guidelines are barely used (0-25\%)

$\square$ Guidelines are used in some cases (25-50\%)

$\square$ Guidelines are used in most cases (50-75\%)

- Guidelines are used nearly always (75-100\%)
}

Fig. 1 Guideline use and guideline adherence among four European countries surveyed

\section{Factors that prompt CT ordering in $\mathrm{mTBI}$ management}

When specifically asked about which factors prompt CT ordering in mTBI a number of different areas of agreement and disagreement among physicians working in different countries was noted (Fig. 2). Most physicians would ask for a CT in anticoagulated patients, but also in patients on platelet inhibitors. CT would also be performed if there are seizures, altered consciousness, any neurological deficit, clinical signs of skull fracture or signs of facial fracture. There is variability in the decision to ask for a CT, but not differences among countries, when the patient is older than 60 years of age, report headaches, have episodes of vomiting, in the occasion of a vulnerable road user (pedestrian or cyclist) that was injured by a passing vehicle, if there are facial contusions, or physical evidence of head trauma or face contusions. Though most physicians would perform a 


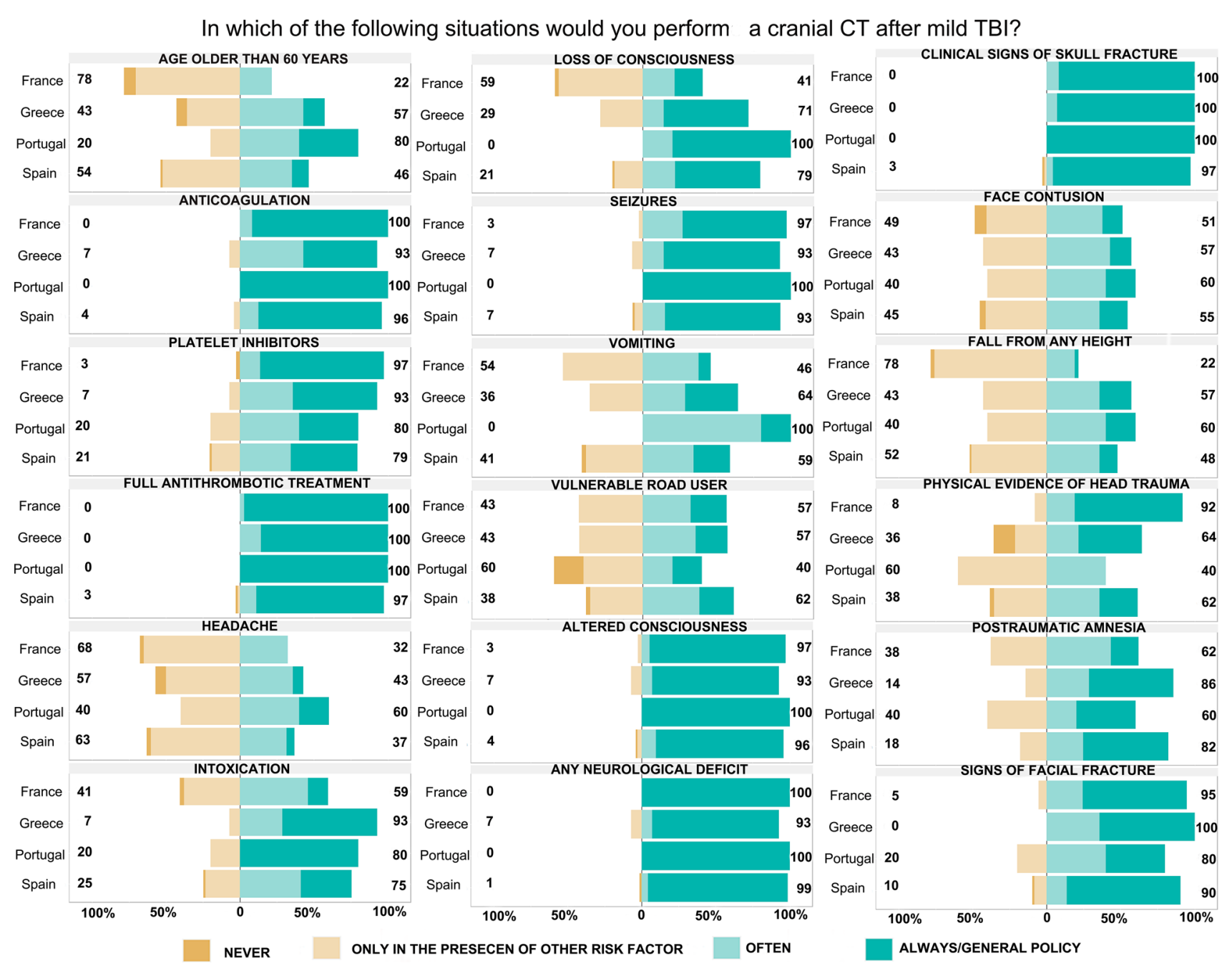

Fig. 2 Factors determining the use of cranial CT

CT in case of a patient presenting with intoxication (altered consciousness due to alcohol, drugs or medications) the percentage of physicians that would perform a CT often or always is smaller in France (59\% vs over 75\% in the rest of the countries). There are significant differences in the indication for CT scan after mild TBI among countries when there is loss of consciousness or posttraumatic amnesia. In both circumstances Spanish doctors would ask more frequently for a CT than the French $(p<0.05$ bootstrap correction for multiple testing).

\section{Response to clinical vignettes}

To better understand physicians' answers in view of the declared guidelines used, a summary of the factors acknowledged as indication for brain CT by these guidelines and the theoretical response to clinical vignettes following these guidelines is presented in Tables 2 and 3. All physicians' answers (188) are shown in Fig. 3. There was agreement in most physicians in the different countries for the patient treated with anticoagulant or platelet inhibitors. Though anticoagulant use is a factor in all guidelines for performing a cranial CT, this is not the case with platelet inhibitors only cited by the Scandinavian Guidelines as a factor that combined with advanced age should determine the indication for a cranial CT. Disorientation in sports-related mTBI would prompt the performance of a cranial CT, though this is not really covered by any guideline. Also, falling from more than a person height show a similar result but with wide variability among physicians, possibly reflecting the lack of agreement between guidelines explicitly citing this factor (dangerous mechanism) as indication for cranial CT. Significant differences among countries regarding cases in which age and loss of consciousness are the main reason for performing a CT scan were seen $(p<0.05$ bootstrap correction for multiple testing) Spanish physicians would perform a CT 
Table 2 Summary of the different factors that prompt the performance of cranial CT after mild TBI in the different management guidelines

\begin{tabular}{|c|c|c|c|c|c|}
\hline & $\begin{array}{l}\text { Canadian } \\
\text { CT head } \\
\text { rule }\end{array}$ & $\begin{array}{l}\text { New } \\
\text { Orleans } \\
\text { criteria }\end{array}$ & NICE & French guideline & Scandinavian guideline \\
\hline \multicolumn{6}{|c|}{ Stand alone Indications for CT after mild TBI explicit in guideline } \\
\hline GCS $<15$ at $2 \mathrm{~h}$ after injury & $\checkmark$ & $\checkmark$ & $\checkmark$ & $\checkmark$ & $\mathrm{S}_{100 \mathrm{~B}}^{*} ; \leq 13$ \\
\hline Seizures & $\checkmark$ & $\checkmark$ & $\checkmark$ & $\checkmark$ & $\checkmark$ \\
\hline Anticoagulation & $\checkmark$ & $\checkmark$ & $\checkmark$ & $\checkmark$ & $\checkmark$ \\
\hline Bleeding disorders & $\checkmark$ & $\checkmark$ & $\checkmark$ & $\checkmark$ & $\checkmark$ \\
\hline Suspected cranial fracture (skull/depressed/cranial base) & $\checkmark$ & $\checkmark$ & $\checkmark$ & & $\checkmark$ \\
\hline Dangerous mechanism (fall from height, pedestrian) & $\checkmark$ & & $\checkmark$ & & \\
\hline Age $>60$ years & Age $>65$ & $\checkmark$ & Age $>65$ & & \\
\hline Vomiting (episodes) & $\geq 2$ & $\checkmark$ & $>1$ & $>1$ & S100B* \\
\hline Retrograde amnesia & $\checkmark$ & $\checkmark$ & $>30 \mathrm{~min}$ & $>30 \min$ & \\
\hline Headache & & $\checkmark$ & & & \\
\hline Intoxication & & $\checkmark$ & & $\checkmark$ & \\
\hline Loss of consciousness & $\dagger$ & $\dagger$ & & $\dagger$ & $\mathrm{S} 100 \mathrm{~B} *$ \\
\hline Evidence of trauma above clavicles & & $\checkmark$ & & & \\
\hline \multicolumn{6}{|l|}{ Combined factors that indicate $\mathrm{CT}$} \\
\hline Age 65 and antiplatelet medication & & & & & $\checkmark$ \\
\hline
\end{tabular}

*S100B: CT should be performed if S100 is not available, or not performed $<6 \mathrm{~h}$, or there is extracranial injury, or S100B performed $<6 \mathrm{~h}$ after injury is $>0.10 \mu \mathrm{g} / \mathrm{l}$

$\nmid$ Canadian CT rule, New Orleans and French Guidelines include loss of consciousness as a factor for defining mild TBI which needs further attention

Table 3 Theoretical response to clinical vignettes following different mTBI management guidelines

\begin{tabular}{|c|c|c|c|c|c|}
\hline Clinical vignette & $\begin{array}{l}\text { Canadian } \\
\text { CT head } \\
\text { rule }\end{array}$ & $\begin{array}{l}\text { New } \\
\text { Orleans } \\
\text { criteria }\end{array}$ & NICE & $\begin{array}{l}\text { French } \\
\text { guide- } \\
\text { line }\end{array}$ & $\begin{array}{l}\text { Scandi- } \\
\text { navian } \\
\text { guideline }\end{array}$ \\
\hline $\begin{array}{l}\text { A } 80 \text {-year-old woman is taken to the emergency room after falling from stairs. She did } \\
\text { not lose consciousness, she has no headache and has no vomiting or nausea. Her clini- } \\
\text { cal examination is normal }\end{array}$ & $\checkmark$ & $\checkmark$ & $\checkmark$ & & \\
\hline $\begin{array}{l}\text { A } 55 \text {-year-old woman is brought to the emergency department after falling from stand- } \\
\text { ing height in the street. She is anticoagulated on apixaban. She has an open wound in } \\
\text { the scalp. She is conscious and GCS }=15 \text {. No headache or nausea }\end{array}$ & $\checkmark$ & $\checkmark$ & $\checkmark$ & $\checkmark$ & $\checkmark$ \\
\hline $\begin{array}{l}\text { A } 23 \text {-year-old man presented to the emergency department after having an impact on } \\
\text { the head while playing football. He remained playing for some time but had to stop } \\
\text { playing due to disorientation. He is GCS }=15 \text { but is complaining of headache. No } \\
\text { vomiting }\end{array}$ & \multicolumn{5}{|c|}{$\begin{array}{l}\text { Disorientation after TBI and TBI in sports are not } \\
\text { covered in the guidelines. There is no clear indica- } \\
\text { tion for CT with these guidelines }\end{array}$} \\
\hline $\begin{array}{l}\text { A } 45 \text {-year-old man is taken to the emergency room after falling from approximately } 2 \mathrm{~m} \\
\text { of height. He has an open wound in the scalp. He did not lose consciousness nor has } \\
\text { nausea or vomiting. GCS }=15\end{array}$ & \multirow[t]{2}{*}{$\checkmark$} & & \multirow{2}{*}{\multicolumn{3}{|c|}{$\checkmark$}} \\
\hline $\begin{array}{l}\text { A } 59 \text {-year-old male presented to the emergency department after falling at home. The } \\
\text { patient experienced a brief loss of consciousness. He has an entirely normal neuro- } \\
\text { logic examination. He has no significant past medical history and takes no routine } \\
\text { medicines }\end{array}$ & & & & & \\
\hline $\begin{array}{l}\text { A } 60 \text {-year-old woman presented to the emergency department } 2 \mathrm{~h} \text { after falling due to a } \\
\text { slippery floor and hitting her head. She is on plavix. She has not loss of consciousness } \\
\text { and has no headaches. GCS }=15\end{array}$ & \multicolumn{5}{|c|}{$\begin{array}{l}\text { No CT indication. Only Scandinavian Guidelines } \\
\text { use antiplatelet treatment but in conjunction with } \\
\text { age }>65\end{array}$} \\
\hline
\end{tabular}

$\checkmark$ Indication for CT scan after mild TBI per guideline criteria 


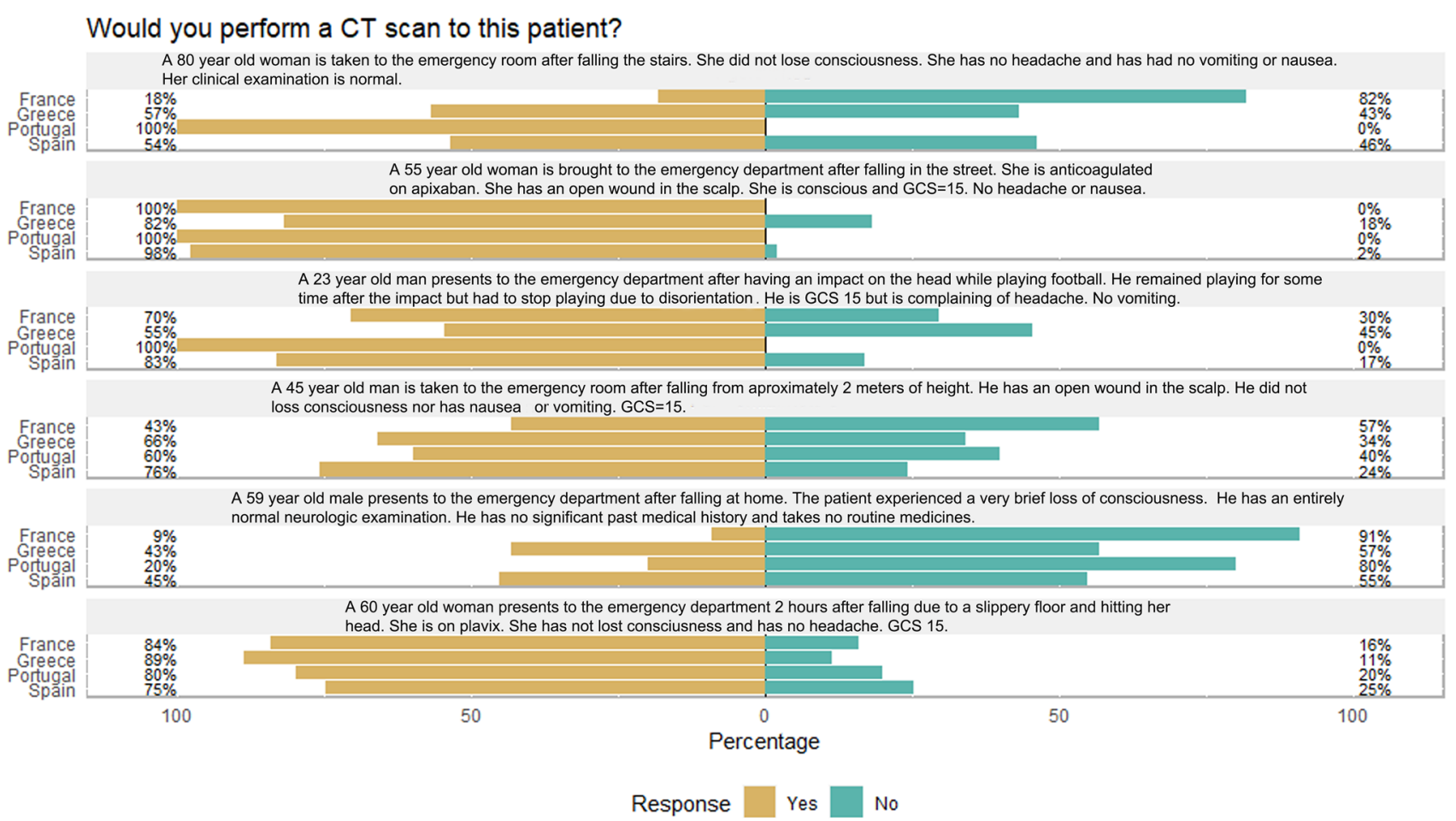

Fig. 3 Responses to clinical vignettes among physicians

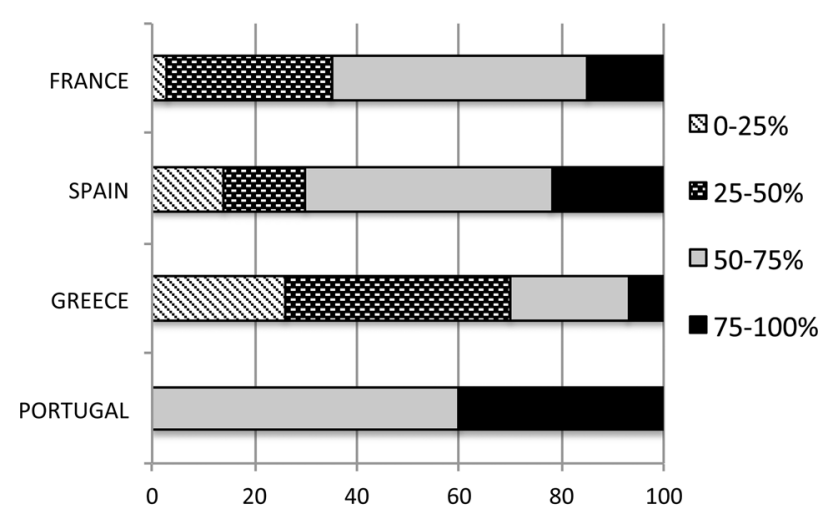

Fig. 4 Physician perceived use of CT in mild TBI management

scan in these patients with a higher frequency and French physicians with lowest frequency than the other countries, in accordance with the wide use of the French guideline which does not include age as a factor for performing cranial CT in these patients..

\section{Estimated usage of $\mathrm{CT}$ and $\mathrm{S} 100 \mathrm{~B}$ in the management of $\mathrm{mTBI}$}

When asked which proportion of mTBI cases would get a CT scan finally at their centres, most physicians answered than in more than $50 \%$ of the cases a CT scan would be performed.
Therefore, the usage of CT scan for the management of mTBI is very high (Fig. 4). However, when asked if this proportion was appropriate or not, most physicians felt it to be appropriate. Only a large proportion of French doctors (47\% of the answers) deemed this proportion to be too high. The use of CT seems to be related to guideline compliance as centres in which no guidelines were used or reported low guideline compliance (less than $25 \%$ of cases) used less frequently CT scan in their patients (57\% responded to use CT in less than $50 \%$ of mTBI cases) than those reporting higher guideline compliance (among centres reporting 50\% or more adherence to guidelines; $68 \%$ use CT in more than in 50\% of mTBI).

The use of S100B in the surveyed countries is anecdotal. Only five centres in France (out of 36, 14\%) used routinely S100B for determining the need for cranial CT in mTBI patients. Most of physicians answered that they did not use S100B due to lack of availability in their centres or lack of knowledge about the test. Therefore, despite being in the market for several years, this solution has not been adopted in these countries.

\section{Discussion}

This study shows that management and guideline adherence in mTBI vary a lot in Southern Europe. There is also variability on the speciality responsible for taking care of these 
patients. No definite consensus on certain conditions that could determine the use of CT in mTBI patients exists, since numerous differences regarding the practical use of CT when physicians are confronted to clinical scenarios were noted. A possible objective means of structuring mTBI management at a biomarker level (i.e., S100B) has not been established in the surveyed countries.

The ED is the first and frequently sole point of medical contact for patients sustaining a mTBI. Though it would seem logical to give an important attention to this health problem, as it is a common cause of consultation to EDs, it seems little attention is paid in many countries. There is a significant local variability regarding which speciality takes care of these patients (emergency medicine, neurosurgery, general surgery, etc.), which could contribute to variability in management and difficulty in offering proper training to physicians. The development of evidenced-based guidelines to manage these patients could contribute in standardizing the management of mTBI and thus decrease variability $[5,7,8]$. However, there is no consensus regarding which guideline to use [11, 18-20]. This factor would not actually compromise management, as the different guidelines present similar criteria to perform CT after mTBI. However, there are developed countries like Spain that declare in a high percentage of cases that centres do not follow any official guideline, and only a minority of centres declare that guidelines are used in most or the majority of their cases.

The available guidelines provide criteria to perform CT based on factors related to patient's characteristics, like age or the use of anticoagulants, factors related to clinical presentation like trauma mechanisms, presence of seizures, loss of consciousness or signs on examination like altered level of consciousness, GCS $<15$ or focal neurological signs $[7,8,10]$. In the current survey, the responses to clinical scenarios made clear that physicians do not agree on age as a sole factor for asking for a CT and physicians do not follow recommendations based exclusively on the loss of consciousness. Physicians seem to believe that the use of antiplatelet agents has a similar effect on terms of presence of intracranial lesions than anticoagulant therapy based on the response to one of the cases.

The findings in this study are in line with previous studies on the management of mTBI in Europe and the US, in which large variations in the assessment and management of mTBI have been detected [14, 20-22]. Moreover areas of controversy previously detected are once again highlighted in the current report, such as age as an indication of cranial CT, loss of consciousness, altered consciousness due to intoxication or the use of platelet inhibitors a factor that is not included in any guideline. It seems that physicians feel safer using CT as screening for these patients, not only for medical reasons but also due to possible malpractice claims, and though most of them feel appropriate to use $\mathrm{CT}$ in more than $50 \%$ of mTBI cases presenting to their EDs, this could add to CT overuse and excessive exposure to radiation [23].

The results of this survey also point out on the median time spent for mTBI management in the ED, which is $8 \mathrm{~h}$. This can represent a long emergency department waiting time for patients, and substantial health resource use for healthcare systems. Part of this time can be attributed to CT waiting, interpretation and analysis. Though radiological interpretation by emergency physicians is possible, in many centres there is a need for neuroradiological interpretation of CT findings to be able to discharge a patient from ED. With higher selectivity for CT ordering some of this time could potentially be decreased for at least a considerable proportion of patients.

Although extensive research has been performed concluding to recommend $\mathrm{S} 100 \mathrm{~B}$ as a means of selecting patients for brain CT scan when in doubt or in grey zone areas [13, 24, 25], its use in a wide region of Southern Europe is limited, as has been previously described in another survey including selected level 1 trauma centres [14]. One of the main reasons for not using this test is its lack of availability.

All above findings give even more importance for medical education for physicians taking care of these patients, in terms of achieving a standardized approach regardless of medical speciality or country. A pan-European multidisciplinary consensus guideline could be feasible and would be ideal to standardize management. There are efforts from different organizations to include specific training for physicians managing these patients in the ED, such as the Emergency Neurological Life Support (ENLS) course from the Neurocritical Care Society, or the Global Neuro Diploma in Neurotrauma Care. In both instances, multidisciplinary approaches try to provide physicians in the ED with a set of protocols, checklists and decision points to standardize the management of these patients around the globe. This study also highlights the need for obtaining an unbiased, quick, radiation free an easy to use test to determine the need for CT, observation or admission for these patients [26, 27].

This study has several limitations. Fist, although we tried to include different Hospitals in terms of sizes and available resources to increase generalizability of the results, limited number of Hospitals were reached in Greece and Portugal. However, the results from France and Spain include a large number of centres with wide geographical distribution in the country and including Hospitals of different sizes. Another limitation is the reliability of the answers from physicians regarding guideline use and adherence. The inclusion of clinical vignettes could have enhanced the contextualization of factors prompting CT prescription in these patients, though there is still some limitation concerning the cases involving intoxication, which were not included in the vignettes. 


\section{Conclusions}

There are large variations in the assessment of mTBI in the European countries surveyed, regarding guideline use and adherence, and individual factors determining the use of $\mathrm{CT}$ as screening tool in these patients. This variation could determine CT overuse. S100B is not used in the majority of European countries. There is a clear need for medical education in Europe to clarify the management of this common clinical problem.

Supplementary Information The online version contains supplementary material available at https://doi.org/10.1007/s00068-022-01902-5.

Acknowledgements BRAINI investigators: Maxime Maignan, Emergency Department, University Hospital, Grenoble, France; Laurent Jacquin, Hospices Civils of Lyon, Emergency department,Edouard Herriot Hospital, Lyon, France; Marion Douplat, Hospices Civils de Lyon,Emergency Department, Lyon, France; Said Laribi, Department of Emergency Medicine, Tours University Hospital, Tours, France; Philippe Pes, Department of Emergency Medicine, University Hospital of Nantes, Nantes, France; Patrick Ray, Emergency Department, University Hospital of Dijon Bourgogne, Dijon, France; Jérémy Guenezan, CHU de Poitiers, Service des Urgences et SAMU 86, Poitiers, France, Université de Poitiers, Faculté de Médecine et de Pharmacie de Poitiers, Poitiers, France; Mustapha Sebbane, Department of Emergency Medicine and Prehospital Care, Montpellier University Hospital, Montpellier, France; Frédéric Balen, Emergency Department, Toulouse University Hospital, Toulouse, France; Guillaume Durand, Hôpital Nord-Ouest Villefranche sur Saône, France; Cordelia Abric, CH Annecy Genevois, FranceCédric Gil-Jardiné, Emergency Department, University Hospital Bordeaux, France; María Teresa Lorca, Servicio de Urgencias, Hospital Universitario del Tajo, Madrid, Spain; Mariana Garcia Ponce, Servicio de Neurocirugía, Instituto de Investigación imas 12, Hospital Universitario 12 de Octubre, Madrid, Spain; Maite Cuesta, Servicio de Neurocirugía, Instituto de Investigación imas 12, Hospital Universitario 12 de Octubre, Madrid, Spain; Jose A. F. Alén, Servicio de Neurocirugia, Hospital Universitario de la Princesa, Madrid, Spain. List of participating Hospitals: France: Hôpital Lariboisière APHP, Centre Hospitalier Cahors, Centre Hospitalier du Pays d'Aix, $\mathrm{CH}$ Bayonne, $\mathrm{CH}$ Chalons en Champagne, $\mathrm{CH}$ du Forez, $\mathrm{CH}$ Genevieve de Gaulle Anthonioz, CH Annecy Genevois, CHRU Nancy, CHU Angers, CHU de la Réunion, CHU de Nantes, CHU Grenoble, CHU Lille, CHU Lyon, CHU Strasbourg, Clinique Saint Charles Lyon, CHU Dijon, Groupe Hospitalier Sud Ile-De-France-Ch De Melun, Hopital Erasme, Hopital Paris Saint-Joseph, Hopital Nord-Ouest de Villefranche, Hôpital-Centre Hospitalier Universitaire (CHU) Toulouse, Hôpitaux Universitaires Pitié Salpêtrière, Hôpitaux Universitaires de Marseille Timone, Centre hospitalier régional universitaire de Tours, CHU Poitiers, CHU Bordeaux, Limoges University Hospital, Hopital Rene Dubois, CHU de Rouen, CHU Rennes, CHU de Montpellier, CHU Limoges, Centre Hospitalier Selestat, CHU Caen. Spain: Hospital Universitario 12 de Octubre (Madrid), Hospital Universitario del Tajo (Madrid), Hospital del Escorial (Madrid), Hospital Alvaro Cunqueiro (Vigo), Hospital Univeritario de Gran Canaria Dr Negrín (las palmas de Gran Canaria), Hospital Universitario de Burgos (Burgos), Hospital Universitario de la Princesa (Madrid), Hospital Universitario de la Paz (madrid), Hospital Virgen del Rocio (Sevilla), Hospital Universitario Gregorio Marañón, Hospital Universitario Váll d’Hebrón (Barcelona), Hospital Comarcal de Melilla (Melilla), Hospital Virgen de las Nieves (Granada), Hospital Universitario de Alava (Vitoria), Hospital Universitario Puerta de Hierro (Madrid), Hospital Mutua Terrasa (Barcelona), Hospital Universitario Puerta del Mar (Cádiz), Hospital Regional de
Málaga (Málaga), Hospital Clínico Universitario Santiago (Santiago de Compostela), Hospital Germans Trias I Pujol (Girona), Hospital Universitario de Alicante (Alicante), Hospital Central de Asturias (Asturias), Hospital Universitari de Bellvitge (Barcelona), Complejo Hospitalario de Navarra (Navarra), Complejo Hospitalario Universitario Insular (Las Palmas de Gran canaria), Hospital Ramón y Cajal (Madrid), Hospital Universiatrio de Torrecardenas (Almeria), Hospital Infanta Elena (Madrid), Hospital Universitario de Torrejón (Madrid), Hospital General de Villalba (Madrid), Hospital Severo Ochoa (Madrid), Hospital HLA Moncloa (Madrid), Hospital Universitario de Guadalajara (Guadalajara), Hospital General Universitario Nuestra Señora del Prado (Toledo), Complejo Hospitalario de Toledo (Toledo), Hospital Universitario Rey Juan Carlos (Madrid), Hospital de Hellín (Albacete), Hospital General de la Defensa Gómez Ulla (Madrid), Hospital General de Valdepeñas (Ciudad Real), Hospital Genral Universitario de Ciudad Real (Ciudad Real), Hospital Nuestra Señora de Sonsoles (Ávila), Complejo Asistencial Universitario de León (León), Centro Asistencial Universitario de Salamanca (Salamanca), Hospital Generald e Segovia (Segovia), Hospital Infanta Sofía (Córdoba), Hospital Santa Bárbara (Soria), Hospital Clínico Universitario de Valladolid (Valladolid), Hospital Universitario de Getafe (Madrid), Hospital Universitario Rio Hortega (Valladolid), HM SanChinarro (Madrid), Hospital de Poniente (Almeria), Nuevo Hospital de la Línea de la Concepción (Cádiz), Hospital Clínico San Cecilio (Granada), Hospital de Jerez (Cádiz), Hospital de alta resolución de Puente Genil (Córdoba), Hospital de Benavente (Zamora), Hospital de Puerto Real (Cádiz), Hospital Infanta Elena (Huelva), Hospital Valme (Sevilla), Empresa Pública Alto Guadalquivir (Jaén), Hospital Universitario Virgen de la Macarena (Sevilla), Hospital Punta de Europa (Cádiz), Hospital Universitario de Jaén (Jaén), Hospital Juan Ramón Jiménez (Huelva), Hospital Niño Jesús (Madrid), Hospital Medina del Campo (Burgos), Hospital Virgen de la Concha (Zamora), Hospital Son Espasses (P. Mallorca), Hospital Campo Grande (Valladolid), Hospital Universitario Son Llatzer (Palma de Mallorca), Hospital Can Misses (Ibiza), Hospital de Formentera (Islas Baleares), Hospital del Bierzo (Léon), Hospital Comarcal INCA (Islas Baleares), Hospital de Santa Bárbara (Soria). Greece: Hippokratio General Hospital Thessalonica, University Hospital Larissa, Larissa General Hospital, KAT General Hospital, General Hospital of TRIPOLI, General Hospital of Giannitsa, Papageorgiou Hospital, University Hospital of Ioannina, General Hospital of Athens Evangelismos, General Hospital of ATTICA, AHEPA University Hospital, General Hospital Nikaia-Pireus Athens. Portugal: Hospital de Santa María (Porto), Centro Hospitalario e Universitario de Coimbra, Centro Hospilaraio Universitário do Algarve, Centro Hospitalario Lisboa Occidental, Braga Public Hospital.

Funding Open Access funding provided thanks to the CRUE-CSIC agreement with Springer Nature. This study is supported in Hospital 12 de Octubre, Univ. Grenoble Alpes and bioMérieux by a grant from the European Institute of Innovation and Technology (EIT) Health (BP 2019-2020). EIT Health is supported by EIT, a body of the European Union.

Data availability statement Data are available on reasonable request. Centre anonymised data are available on reasonable request. Data will be provided for health care policies preparation, or to be part of larger studies.

\section{Declarations}

Conflict of interest Vlad Pavlov and Odile Mejan are employees of bioMérieux. 
Open Access This article is licensed under a Creative Commons Attribution 4.0 International License, which permits use, sharing, adaptation, distribution and reproduction in any medium or format, as long as you give appropriate credit to the original author(s) and the source, provide a link to the Creative Commons licence, and indicate if changes were made. The images or other third party material in this article are included in the article's Creative Commons licence, unless indicated otherwise in a credit line to the material. If material is not included in the article's Creative Commons licence and your intended use is not permitted by statutory regulation or exceeds the permitted use, you will need to obtain permission directly from the copyright holder. To view a copy of this licence, visit http://creativecommons.org/licenses/by/4.0/.

\section{References}

1. Steyerberg EW, Wiegers E, Sewalt C, Buki A, Citerio G, De Keyser V, et al. Case-mix, care pathways, and outcomes in patients with traumatic brain injury in CENTER-TBI: a European prospective, multicentre, longitudinal, cohort study. Lancet Neurol. 2019;18(10):923-34.

2. Gómez PA, Lobato RD, Ortega JM, De La Cruz J. Mild head injury: differences in prognosis among patients with a Glasgow Coma Scale score of 13 to 15 and analysis of factors associated with abnormal CT findings. Br J Neurosurg. 1996;10(5):453-60.

3. Levin HS, Diaz-Arrastia RR. Diagnosis, prognosis, and clinical management of mild traumatic brain injury. Lancet Neurol. 2015;14:506-17.

4. Gomez PA, Lobato RD, Lagares A, Alen JF. Mild head injury in adults. A review. Neurocirugia. 2000;11(5):351-63.

5. Ibañez J, Pedraza S, Sánchez E, Poca MA, Rodriguez D, Rubio E. Reliability of clinical guidelines in the detection of patients at risk following mild head injury: results of a prospective study. J Neurosurg. 2004;100:825-34.

6. Silverberg ND, Iaccarino MA, Panenka WJ, Iverson GL, McCulloch KL, Dams-O'Connor K, et al. Management of concussion and mild traumatic brain injury: a synthesis of practice guidelines. Arch Phys Med Rehab. 2020;101:382-93.

7. Stiell IG, Wells GA, Vandemheen K, Clement C, Lesiuk H, Laupacis A, et al. The Canadian CT head rule for patients with minor head injury. Lancet. 2001;357(9266):1391-6.

8. Haydel MJ, Preston CA, Mills TJ, Luber S, Blaudeau E, DeBlieux PMC. Indications for computed tomography in patients with minor head injury. N Engl J Med. 2000;343(2):100-5.

9. National Institute for Health and Care Excellence (2014) Head Injury: assessment and early management. (NICE Guideline 176). Available at https://www.nice.org.uk/guidance/cg176. Accessed 20 Sept 2021.

10. Jehlé E, Honnart D, Grasleguen C, Bouget J, Dejoux C, Lestavel $\mathrm{P}$, et al. Traumatisme crânien léger (score de Glasgow de 13 à 15): triage, évaluation, examens complémentaires et prise en charge précoce chez le nouveau-né, l'enfant et l'adulte. Ann Fr Med d'Urgence. 2012;2(3):199-214.

11. Foks KA, Cnossen MC, Dippel DWJ, Maas AIR, Menon D, Van Der Naalt J, et al. Management of mild traumatic brain injury at the emergency department and hospital admission in Europe: a survey of 71 neurotrauma centers participating in the CENTERTBI study. J Neurotrauma. 2017;34:2529-35.
12. Zetterberg H, Blennow K. Fluid biomarkers for mild traumatic brain injury and related conditions. Nat Rev Neurol. 2016;12:563-74.

13. Calcagnile $\mathrm{O}$, Anell A, Undén J. The addition of S100B to guidelines for management of mild head injury is potentially cost saving. BMC Neurol. 2016;16(1):200.

14. Undén J, Ingebrigtsen T, Romner B. Scandinavian guidelines for initial management of minimal, mild and moderate head injuries in adults: an evidence and consensus-based update. BMC Med. 2013;11(1):50.

15. Richard M, Lagares A, Bondanese V, De La Cruz J, Mejan O, Pavlov V, et al. Study protocol for investigating the performance of an automated blood test measuring GFAP and UCH-L1 in a prospective observational cohort of patients with mild traumatic brain injury: European BRAINI study. BMJ Open. 2021;11(2):1-6.

16. García-Pérez MA, Núñez-Antón V, Alcalá-Quintana R. Analysis of residuals in contingency tables: another nail in the coffin of conditional approaches to significance testing. Behav Res Methods. 2015;47(1):147-61.

17. Speerschneider JB, Likert K (2016) Analysis and visualization likert items. [Internet]. R package version 1.3.5. Available from: https://cran.r-project.org/package=likert

18. Jones LA, Morley EJ, Grant WD, Wojcik SM, Paolo WF. Adherence to head computed tomography guidelines for mild traumatic brain injury. West J Emerg Med. 2014;15(4):459-64.

19. Brown AM, Twomey DM, Shee AW. Evaluating mild traumatic brain injury management at a regional emergency department. Inj Prev. 2018;24(5):390-4.

20. Pülhorn H, Westmoreland L, McMahon C. The management of minor head trauma (GCS 15-13) across a Trauma Network. Br J Neurosurg. 2016;30(5):536-40.

21. De Kruijk JR, Twijnstra A, Meerhoff S. Management of mild traumatic brain injury: lack of consensus in Europe. Brain Inj. 2001;15(2):117-23.

22. Stern RA, Seichepine D, Tschoe C, Fritts NG, Alosco ML, Berkowitz $\mathrm{O}$, et al. Concussion care practices and utilization of evidence-based guidelines in the evaluation and management of concussion: a survey of New England emergency departments. J Neurotrauma. 2017;34:861-8.

23. Melnick ER, Szlezak C, Bentley S, Dziura J, Kotlyar S, Post L. CT overuse for mild traumatic brain injury. Jt Comm J Qual Patient Saf. 2012;38(11):483-9.

24. Kelmendi FM, Morina AA, Mekaj AY, Blyta A, Alimehmeti R, Dragusha S, et al. Serum S100B levels can predict computed tomography findings in Paediatric patients with mild head injury. Biomed Res Int. 2018;2018:6954045.

25. Thelin EP, Nelson DW, Bellander BM. A review of the clinical utility of serum S100B protein levels in the assessment of traumatic brain injury. Acta Neurochir (Wien). 2017;159(2):209-25.

26. Bazarian JJ, Biberthaler P, Welch RD, Lewis LM, Barzo P, Bogner-Flatz V, et al. Serum GFAP and UCH-L1 for prediction of absence of intracranial injuries on head CT (ALERT-TBI): a multicentre observational study. Lancet Neurol. 2018;17(9):782-9.

27. Papa L, Brophy GM, Welch RD, Lewis LM, Braga CF, Tan CN, et al. Time course and diagnostic accuracy of glial and neuronal blood biomarkers GFAP and UCH-L1 in a large cohort of trauma patients with and without mild traumatic brain injury. JAMA Neurol. 2016;73(5):551-60. 